\title{
Casein Kinase II Is Required for Efficient Transcription by RNA Polymerase III
}

\author{
DARREN J. HOCKMAN AND MICHAEL C. SCHULTZ* \\ Department of Biochemistry, University of Alberta, Edmonton, Alberta, Canada T6G $2 H 7$
}

Received 13 October 1995/Returned for modification 21 November 1995/Accepted 7 December 1995

\begin{abstract}
Casein kinase II (CKII) is a ubiquitous and highly conserved serine/threonine protein kinase found in the nucleus and cytoplasm of most cells. Using a combined biochemical and genetic approach in the yeast Saccharomyces cerevisiae, we assessed the role of CKII in specific transcription by RNA polymerases I, II, and III. CKII is not required for basal transcription by RNA polymerases I and II but is important for polymerase III transcription. Polymerase III transcription is high in extracts with normal CKII activity but low in extracts from a temperature-sensitive mutant that has decreased CKII activity due to a lesion in the enzyme's catalytic $\alpha^{\prime}$ subunit. Polymerase III transcription of 5S rRNA and tRNA templates in the temperature-sensitive extract is rescued by purified, wild-type CKII. An inhibitor of CKII represses polymerase III transcription in wild-type extract, and this repression is partly overcome by supplementing reaction mixtures with active CKII. Finally, we show that polymerase III transcription in vivo is impaired when CKII is inactivated. Our results demonstrate that CKII, an oncogenic protein kinase previously implicated in cell cycle and growth control, is required for high-level transcription by RNA polymerase III.
\end{abstract}

Casein kinase II (CKII) is a ubiquitous and highly conserved serine/threonine kinase that is found in the nucleus and the cytoplasm of most cells (reviewed in references 29, 36, 45, and 54). It is usually composed of two functionally redundant catalytic subunits, $\alpha$ and $\alpha^{\prime}$, and a regulatory subunit, $\beta$.

CKII appears to play critical roles in cell cycle control and in growth control. Metazoan and yeast cells require CKII for progression through $\mathrm{G}_{1}(23,43)$, and yeast cells further require CKII for completion of $\mathrm{G}_{2} / \mathrm{M}$ (23). In yeast cells, CKII is essential for vegetative growth (37), and it is essential in some human cells for the mitogenic response to growth stimuli (44, $50)$. A role in growth control is further suggested by the striking observation that modest overexpression of CKII $\alpha$ leads to tumorigenesis in mice (50). The view that CKII is important in cell cycle and growth control is also supported by the observations that bulk CKII activity fluctuates during the cell cycle (9) and in parallel with changes in growth rate $(2,9,40)$.

While CKII clearly plays a significant role in cell growth and division, the molecular basis of its involvement in these processes remains to be fully elucidated (reviewed in references 29, 36, and 39). Perhaps of critical importance is the function of CKII in transcription. RNA synthesis as measured by the incorporation of $\left[{ }^{14} \mathrm{C}\right]$ uracil into RNA is reduced fourfold when CKII is inactivated by shifting a yeast mutant of CKII to the restrictive temperature (23). This finding suggests a positive role for CKII in the regulation of transcription. The specific requirement for CKII has so far been reported to involve nuclear RNA polymerases I and II. CKII stimulates run-on transcription by RNA polymerase $\mathrm{I}$ in nuclei isolated from mammalian cells (2), and it can phosphorylate the region of a murine polymerase I transcription factor (UBF) that is required for high basal transcription in vitro (56). CKII may also be required for the functions of some transactivators of polymerase II genes, for example, p53 and PU.1 (reviewed in reference 36 ).

\footnotetext{
* Corresponding author. Mailing address: Department of Biochemistry, University of Alberta, Edmonton, Alberta, Canada T6G $2 \mathrm{H} 7$. Phone: (403) 492-9144. Fax: (403) 492-9556. Electronic mail address: michael.schultz@ualberta.ca.
}

In this study, we used a combined biochemical and genetic approach in the yeast Saccharomyces cerevisiae to further investigate the role of CKII in the regulation of nuclear transcription. We find that in yeast cells, CKII is required for active transcription of the tRNA and 5S rRNA genes by RNA polymerase III, both in vitro and in vivo. The requirement for CKII in transcription may therefore extend to all three classes of nuclear genes in eukaryotes.

\section{MATERIALS AND METHODS}

Materials. 2,3-Diphosphoglycerate, heparin (sodium salt), and S1 nuclease were from Sigma. Yeast extract and Bacto Peptone were from Difco. The CKII peptide substrate was prepared by the Alberta Peptide Institute. It was purified to $>95 \%$ homogeneity by high-pressure liquid chromatography and checked by amino acid analysis and mass spectrometry. Oligonucleotides were synthesized by the DNA Core Facility of the Biochemistry Department, University of Alberta, and purified by gel electrophoresis. CKII (gift of C. V. C. Glover, University of Georgia) was purified to $95 \%$ homogeneity from commercial yeast as described by Bidwai et al. (5). This protocol includes the use of high-salt buffers to prevent the formation of CKII filaments and $\alpha$-subunit aggregates (4).

Strains. CKII mutants were generated from a CKA1 CKA2 strain, YPH250 (51), by Hanna et al. (23). Strains YDH6 (a cka1- $1:: H I S 3 \Delta c k a 2:: T R P 1$ ura3-52 ade2-101 ${ }^{\text {ochre }}$ his3- $\Delta 200$ leu2- $\Delta 1$ lys2-801 ${ }^{\text {amber }}$ trp1- $\Delta 1$ [pDH6 CEN4/ARSH4 LEU2 CKA2]) and YDH8 (a cka1- $1:: H I S 3 \Delta c k a 2::$ TRP1 ura3-52 ade2-101 ochre

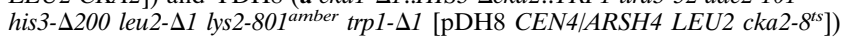
were provided by C. V. C. Glover. We refer to these strains as CKA2 and cka2 ${ }^{\text {ts }}$.

Preparation of yeast transcription extracts. Whole cell extracts were prepared as described by Schultz et al. (47) except that chymostatin was omitted from the proteinase inhibitor cocktail. Cells were grown to an optical density at $600 \mathrm{~nm}$ of 3 in YPD. Cell density measurements were performed after making the medium $20 \mathrm{mM}$ EDTA ( $\mathrm{pH} 8$ ) to disperse clumped cells (41). Temperature shifts were performed in a shaking water bath.

CKII assay. The CKII assay was modified from published procedures $(4,34$ 42). The reactions were performed in $25 \mu \mathrm{l}$, using the specific peptide substrate RRREEETEEE (34) at $250 \mu \mathrm{M}$. Reactions were performed under the conditions for polymerase I and III transcription (see below) (49). Each reaction mixture contained $37.5 \mu \mathrm{g}$ of extract protein and $20 \mathrm{mM} \mathrm{N}$-2-hydroxyethylpiperazine- $N$ '-2-ethanesulfonic acid (HEPES), $50 \mathrm{mM} \mathrm{KCl,} 10 \mathrm{mM} \mathrm{MgCl}_{2}, 5 \mathrm{mM}$ EGTA, $0.1 \mathrm{mM}$ EDTA, $2.5 \mathrm{mM}$ dithiothreitol, $20 \mu \mathrm{g}$ of $\alpha$-amanitin per ml, 100 $\mu \mathrm{M}$ unlabeled ATP, and $1 \mu \mathrm{l}$ of $\left[\gamma_{-}{ }^{32} \mathrm{P}\right] \mathrm{ATP}(3,000 \mu \mathrm{Ci} / \mathrm{mmol} ; \mathrm{NEN})$. These conditions were varied only in the case of CKII add-back experiments, which used $22.5 \mathrm{mM} \mathrm{KCl}$ and $75 \mathrm{mM} \mathrm{NaCl}$ in place of the $50 \mathrm{mM} \mathrm{KCl}$ usually used. This modification was necessary because CKII is stored in a high-salt buffer (see below). The reaction in a $20-\mu l$ aliquot from each assay mixture was stopped after 5 min of incubation at $22^{\circ} \mathrm{C}$ by spotting onto Whatman P81 paper. Further processing and quantitation by scintillation counting were as described previ- 
A.

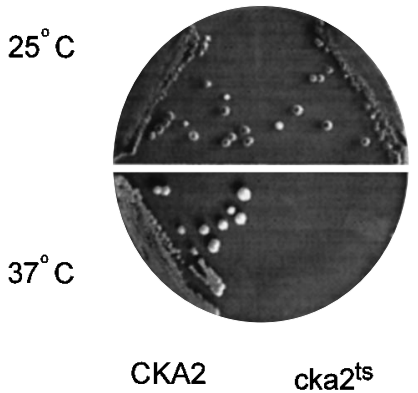

B.



FIG. 1. (A) Growth phenotypes of CKA2 and cka2 $2^{\text {ts }}$ cells at the permissive temperature, $25^{\circ} \mathrm{C}$, and at the restrictive temperature, $37^{\circ} \mathrm{C}$. (B) $\mathrm{CKII}$ activity is deficient in extracts from cka $2^{\text {ts }}$ cells. Enzyme activities of strains CKA2 and cka $2^{\text {ts }}$ are compared. Activity was measured at $22^{\circ} \mathrm{C}$ in extracts from cells grown at $25^{\circ} \mathrm{C}($ left $)$ or grown at $25^{\circ} \mathrm{C}$ and then shifted for $1 \mathrm{~h}$ to $37^{\circ} \mathrm{C}$ (right). Activity ( \pm standard error) is normalized to $100 \%$ for extracts from $\mathrm{CKA} 2$ cells grown at $25^{\circ} \mathrm{C}$.

ously (34). Reactions were performed in triplicate. Standard error bars (for the mean) represent the results from five independent experiments.

The validity of the assay under transcription conditions was confirmed by its sensitivity to heparin, which is a specific inhibitor of CKII $(4,26,45)$ and completely blocks peptide-specific incorporation of ${ }^{32} \mathrm{P}$ at $1 \mu \mathrm{g} / \mathrm{ml}$ in our reactions. Using heparin, we investigated the usefulness of casein as a specific substrate for CKII activity in the transcription extract. We found that two-thirds of the label incorporation into dephosphorylated casein is due to enzymes besides CKII (not shown). The peptide substrate was therefore used for all experiments with the transcription extract.

In vitro transcription reactions. Transcription reactions were performed in 20 $\mu \mathrm{l}$ at $22^{\circ} \mathrm{C}$, using supercoiled templates as described by Schultz et al. (49). Results are shown for $5 \mathrm{~S}$ reactions using template pY5S (49) and for tRNA ${ }^{\text {Leu }}$ reactions using template pGE2 (1). Except where otherwise indicated, the reaction mixtures contained $30 \mu \mathrm{g}$ of extract protein and $400 \mathrm{ng}$ of pY5S or $25 \mathrm{ng}$ of pGE2. For the CKII add-back experiments, all reaction mixtures contained 22.5 $\mathrm{mM} \mathrm{KCl}$ and $75 \mathrm{mM} \mathrm{NaCl}$ in place of $50 \mathrm{mM} \mathrm{KCl}$. We expected that maximal rescue by CKII would be achieved by preincubating the transcription extract with CKII and ATP. This protocol, however, is inefficient because the extract contains an ATP-dependent repressor that can mask the stimulatory effect of CKII (19). To minimize this effect, reaction components were mixed on ice as follows. A template-salts- $\alpha$-amanitin mix (all components except the nucleotides, CKII, and extract) was dispensed into each tube. Separate aliquots of nucleotides and CKII were then spotted onto the wall of the tube and washed into the templatesalts- $\alpha$-amanitin mix with the extract.

S1 protection analysis of in vivo transcription by RNA polymerase III. Cells were grown in YPD at $25^{\circ} \mathrm{C}$ to an $A_{600}$ of 0.4 , and temperature shifts were performed as described by Cormack and Struhl (12) for monitoring polymerase III transcription in temperature-sensitive $(t s)$ yeast strains. Total cellular RNA was isolated as described by Cross and Tinkelenberg (13) and hybridized to completion at $65^{\circ} \mathrm{C}$ with ${ }^{32} \mathrm{P}$-labeled oligonucleotide probes purified by gel electrophoresis. Hybridization was in $30 \mu$ l containing $10 \mathrm{mM}$ Tris- $\mathrm{HCl}$ (pH 7.5), 300 $\mathrm{mM} \mathrm{NaCl}$, and $1 \mathrm{mM}$ EDTA. Probes were added in twofold excess of the amount required to detect the strongest signal in an experiment. S1 nuclease digestion was performed for $1 \mathrm{~h}$ at $37^{\circ} \mathrm{C}$ after addition of $270 \mu \mathrm{l}$ of buffer containing 200 $\mathrm{U}$ of $\mathrm{S} 1$ nuclease, $50 \mathrm{mM} \mathrm{NaCl}, 30 \mathrm{mM}$ sodium acetate $(\mathrm{pH} 6), 1 \mathrm{mM}$ zinc sulfate, and $5 \%$ glycerol. tRNA ${ }^{\text {Trp }}$ transcription was monitored by using probe tRNA $^{\mathrm{W}}$ of Cormack and Struhl (12). To check equivalence of loading, the samples were also probed for $26 \mathrm{~S}$ rRNA. Because $26 \mathrm{~S}$ rRNA is so abundant, aliquots of each RNA preparation were diluted 1:20 with Tris-EDTA buffer before hybridization. The $26 \mathrm{~S}$ rRNA probe detects sequences in the highly conserved structural core of the large rRNA subunit. It is complementary to residues 2528 to 2568 of the $S$. cerevisiae sequence in the numbering scheme of Hassouna et al. (25) and has a 6-bp overhang at the $3^{\prime}$ end (underlined in the sequence below) that is not complementary to the rRNA. This overhang is removed in complete $\mathrm{S} 1$ reactions, leaving a protected fragment of 40 residues. The probe has the sequence 5 '-CTGTTCACCT TGGAGACCTG CTGCGGTTAT CAGTACGACC ATAGGC.

Computer methods. Autoradiographs were scanned with an Apple OneScanner running Ofoto 2.0.2 software on a Macintosh 8100/80 PowerPC. The contrast of an entire scan was in some cases adjusted by using the "balance exposure" command. Images were exported into Canvas 3.5.3b for labeling.

\section{RESULTS}

CKII activity is deficient in transcription extract from a $t s$ mutant of CKII. We have established a system in which tran- scription can be studied as a function of CKII activity in a whole cell extract from $S$. cerevisiae. The $\alpha$ and $\alpha^{\prime}$ subunits of CKII in $S$. cerevisiae are encoded by the $C K A 1$ and $C K A 2$ genes. Our initial experiments have taken advantage of two strains (23): CKA2, which has the wild-type version of the $C K A 2$, and its isogenic partner, strain $\mathrm{cka}^{\mathrm{ts}}$, which carries a $t s$ allele of $c k a 2$ (cka2-8). In both strains, the chromosomal $C K A 1$ and $C K A 2$ genes are disrupted and the $\alpha^{\prime}$ gene is carried on a plasmid. The cells are viable at $25^{\circ} \mathrm{C}$ because the $\alpha$ and $\alpha^{\prime}$ subunits are functionally redundant for catalytic activity $(10$, 41). The $t s$ growth phenotype of cka $2^{\text {ts }}$ conferred by the $c k a 2-8$ allele is illustrated in Fig. 1A. Strains CKA2 and cka2 ${ }^{\text {ts }}$ form colonies of similar sizes when grown on YPD at $25^{\circ} \mathrm{C}$ (Fig. $1 \mathrm{~A}$, top sector). At $37^{\circ} \mathrm{C}$, CKA2 forms large colonies, whereas no visible colonies result from the plating of $\mathrm{cka} 2^{\text {ts }}$ cells (bottom sector).

Glover and colleagues have reported that bulk CKII activity is deficient in strain cka $2^{\text {ts }}$ compared with strain CKA2 (unpublished observations discussed in references 8 and 23). We tested if an extract that preserves transcription by RNA polymerases I, II, and III also preserves the difference in CKII activity between these strains. Extracts were made by a cellular disruption protocol under liquid nitrogen $(47,49)$, and CKII activity was measured by using a specific peptide substrate for CKII, RRREEETEEE (34). Figure 1B compares CKII activities in extracts from cells harvested after growth at $25^{\circ} \mathrm{C}$ or after growth at $25^{\circ} \mathrm{C}$ followed by $1 \mathrm{~h}$ of culture at $37^{\circ} \mathrm{C}$. The results are expressed relative to activity in CKA2 cells grown at $25^{\circ} \mathrm{C}$, which is arbitrarily assigned a value of $100 \%$. The enzyme measurements reveal that transcription extracts from cells harboring the cka2-8 allele are deficient in bulk CKII activity whether or not the cells have been shifted to the restrictive temperature. For cells grown at $25^{\circ} \mathrm{C}$, the cka $2^{\text {ts }}$ extract has only $6 \%$ of the activity of the CKA2 extract; for cells grown at $37^{\circ} \mathrm{C}$, (Fig. $1 \mathrm{~B}$, right panel), the cka $2^{\text {ts }}$ extract has only $15 \%$ the activity of the CKA2 extract (Fig. 1B). The difference in activity between the 25 and $37^{\circ} \mathrm{C} \mathrm{cka2}{ }^{\text {ts }}$ extracts is not statistically significant $(P<0.005)$. From these results, we conclude that the $\mathrm{Cka} 2-8^{\text {ts }}$ protein is defective for bulk CKII activity in the transcription extract.

Polymerase III transcription is specifically defective in extracts lacking CKII activity. The CKII activity measurements in Fig. 1B were performed under the conditions used for transcription by RNA polymerases I and III $(47,49)$ except that the DNA template was omitted, ATP replaced the nucleotide mix used for transcription, and a peptide substrate for CKII was 


\section{A. Permissive}

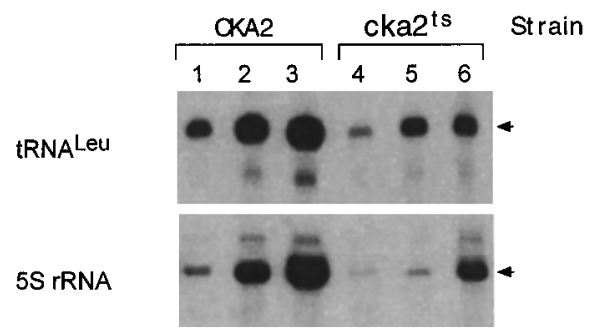

\section{B. Restrictive}

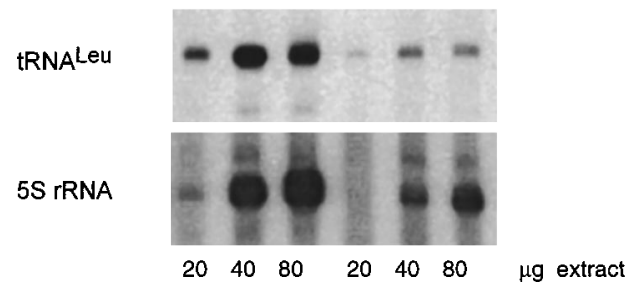

FIG. 2. Transcription by RNA polymerase III is deficient in extracts with low CKII activity. Polymerase III transcription activities in extracts from CKA2 (lanes 1 to 3 ) and cka2 ${ }^{\text {ts }}$ (lanes 4 to 6 ) cells were compared. Run-on transcription assays were performed at $22^{\circ} \mathrm{C}$ in extracts from cells grown at $25^{\circ} \mathrm{C}$ (A) or grown at $25^{\circ} \mathrm{C}$ and then shifted for $1 \mathrm{~h}$ to $37^{\circ} \mathrm{C}(\mathrm{B})$. Transcription activities are compared over a fourfold range of extract concentrations. The arrows show the positions of the expected primary transcripts. Minor bands in the tRNA reactions are processing products, and the slowly migrating band in the $5 \mathrm{~S}$ reaction is a natural transcription product of unknown significance (29). Note that although the levels of transcription differ between the extracts, for a given template the extracts produce products of the same size, and the ratios of primary transcript to processed products in the extracts are similar.

included. Because CKII activity differences are preserved under transcription conditions, we were able to assess transcription in vitro as a function of CKII activity in the extract.

Basal transcription by the three nuclear RNA polymerases was assayed in extracts from cells that had either been cultured at the permissive temperature and harvested or cultured at the permissive temperature and then harvested after culture for 1 $\mathrm{h}$ at the restrictive temperature. Initiation by RNA polymerase I on a template that contained the entire $35 \mathrm{~S}$ gene promoter was identical in extracts from both strains (not shown). Basal transcription by RNA polymerase II on the CYC1 promoter was also similar between the strains (not shown). In contrast, the level of transcription by RNA polymerase III was clearly deficient in $\mathrm{cka}^{\mathrm{ts}}$ extracts. Transcription of a tRNA ${ }^{\mathrm{Leu}}$ gene (Fig. 2, tRNA ${ }^{\mathrm{Leu}}$ ) was defective in $\mathrm{cka}^{\text {ts }}$ extracts compared with CKA2 extracts over a wide range of protein concentrations. $\mathrm{tRNA}^{\mathrm{Leu}}$ transcription was defective in $\mathrm{cka}^{\text {ts }}$ extracts whether or not the cells had been cultured at the restrictive temperature (compare tRNA ${ }^{\text {Leu }}$ transcription in Fig. $2 \mathrm{~A}$ and B). These effects were also observed for the 5S rRNA gene (Fig. 2, 5S rRNA). Therefore, extracts from cka $2^{\text {ts }}$ cells grown at the permissive temperature are deficient for polymerase III transcription (Fig. 2A). We note that CKII activity is also severely impaired in extracts from cka2 $2^{\text {ts }}$ cells that had not been heat shocked (Fig. 1B). Since polymerase III transcription is impaired in all extracts with low CKII activity (six extracts were tested), we propose that the protein kinase activity of CKII is required for high-level transcription of the $5 \mathrm{~S}$ and tRNA genes by RNA polymerase III.

Several trivial effects that could account for these results were ruled out. Cell extracts often differ in the protein concentration required for optimum transcription. The observed

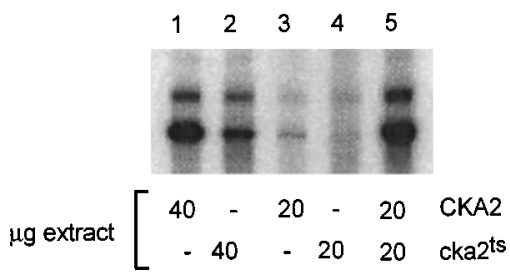

FIG. 3. Transcription of the $5 \mathrm{~S}$ rRNA gene in a mixing experiment using extracts from CKA2 and cka2 $2^{\text {ts }}$ cells grown at $25^{\circ} \mathrm{C}$ and then shifted for $1 \mathrm{~h}$ to $37^{\circ} \mathrm{C}$.

difference between CKA2 and $\mathrm{cka} 2^{\text {ts }}$ extracts could, in principle, be explained by a simple shift in the protein optimum. The result for tRNA ${ }^{\text {Leu }}$ transcription in Fig. $2 \mathrm{~B}$ argues against this possibility. Transcription in the $\mathrm{cka} 2^{\text {ts }}$ extract slightly declines between 40 and $80 \mu \mathrm{g}$ of input protein, indicating that its optimum lies in this interval. Even at this optimum, transcription in the $\mathrm{cka}^{\text {ts }}$ extract is severely impaired compared with the same amount of the CKA2 extract, which seems to encompass the broad optimum for this extract. Induction of nucleases that degrade the template (15) and/or the product during a transcription reaction could also account for the results in Fig. 2. We examined the fate of the template during reactions at 25 and $30^{\circ} \mathrm{C}$ and found no evidence of DNA degradation (not shown). Since the transcription extract contains a variety of cellular RNAs, the fate of these preexisting RNAs during a transcription reaction was monitored by using a sensitive S1 nuclease protection assay (12). There was no detectable degradation of a tryptophan tRNA intron or 26S rRNA during reactions at 25 and $30^{\circ} \mathrm{C}$ (not shown), and so the transcription results cannot be explained by the induction of a novel ribonuclease when CKII activity is low.

CKII activity is required for transcription by RNA polymerase III in vitro. We performed a mixing experiment to test if polymerase III transcription is low in cka $2^{\text {ts }}$ extracts because they lack CKII activity. The rationale of the experiment is that in a mixture of CKA2 and cka $2^{\text {ts }}$ extracts, active CKII from the CKA2 extract will rescue the $t s$ extract if its low transcription activity results from the lack of CKII activity. The experiment, shown in Fig. 3, was performed with extracts from cells cultured for $1 \mathrm{~h}$ at the restrictive temperature. Transcription activities in the extracts were compared by using $40 \mu \mathrm{g}$ of protein per reaction (lanes 1 and 2). The CKA2 extract is about threefold more active than the $\mathrm{cka} 2^{\text {ts }}$ extract under the conditions used. This relative difference is preserved when $20 \mu \mathrm{g}$ of extract is present in each reaction (lanes 3 and 4). Twentymicrogram aliquots of the two extracts were mixed, giving the same total protein as in lanes 1 and 2. The transcription signal from the $20-\mu \mathrm{g}$ mixture (lane 5) is the same as that from $40 \mu \mathrm{g}$ of the CKA2 extract (lane 1), indicating that an activity in the CKA2 extract does rescue the cka2 ${ }^{\text {ts }}$ extract. This activity most likely is CKII. This result supports the hypothesis that the catalytic activity of CKII is required for transcription by RNA polymerase III.

To more rigorously test this hypothesis, we attempted to rescue transcription in the cka $2^{\text {ts }}$ extract with purified $(95 \%)$, enzymatically active CKII prepared as described by Bidwai et al. (4) and kindly provided by C. V. C. Glover. Because CKII is stored in $1 \mathrm{M} \mathrm{NaCl}$, all reactions represented in Fig. 4 and 5 were adjusted to the same final salt concentration by the addition of appropriate amounts of CKII buffer without enzyme (see Materials and Methods). The purified enzyme was added in increasing amounts to $30 \mu \mathrm{g}$ of the cka $2^{\text {ts }}$ extract, which has very low CKII activity on its own (Fig. 2 and 4A). Figure 4A 
A.

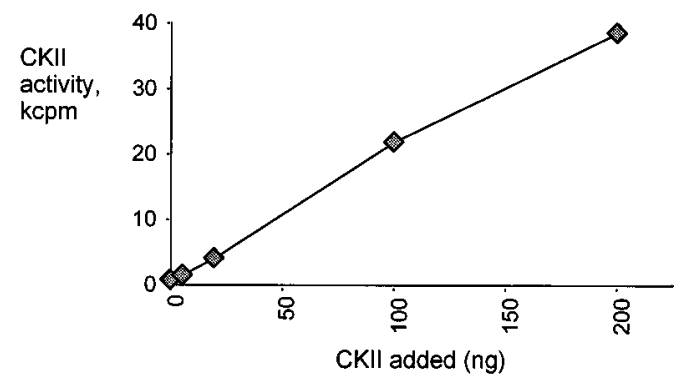

B.

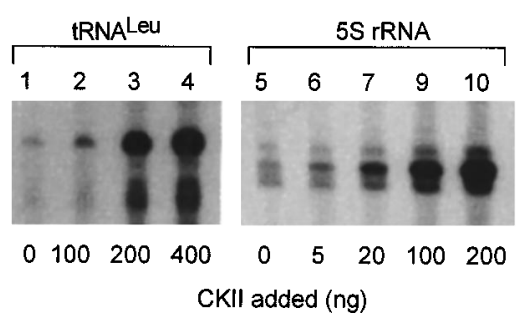

FIG. 4. Rescue of CKII activity (A) and tRNA ${ }^{\text {Leu }}$ and 5 S rRNA transcription (B) by addition of purified CKII to extracts from ckats $2^{\text {ts }}$ cells grown at $25^{\circ} \mathrm{C}$. CKII activity (the average of two experiments) is expressed as counts per minute incorporated during a 5-min reaction.

shows that there is a dose-dependent increase in CKII activity when the purified enzyme is titrated into the cka2 $2^{\text {ts }}$ extract. Figure 4B, lanes 1 to 4 , shows a strict, dose-dependent stimulation of polymerase III transcription on the tRNA ${ }^{\text {Leu }}$ gene as a result of the addition of catalytically active CKII. The same result was obtained when the 5S rRNA gene was used (Fig. 4B, lanes 5 to 10). Therefore, the level of polymerase III transcription directly correlates with the level of CKII activity in a reaction. From these experiments, we conclude that CKII is required for active transcription of the $5 \mathrm{~S}$ and tRNA genes by RNA polymerase III.

The experiments described above rely on the use of yeast strains with mutations in the $C K A 1$ and $C K A 2$ genes. Although unlikely, our findings could result from indirect genetic effects that never occur in normal cells. We therefore devised an alternative biochemical approach to obtain evidence that polymerase III transcription requires CKII in wild-type cells. We examined the effects on transcription of an inhibitor of CKII activity, 2,3-diphosphoglycerate $(38,45,54)$. The inhibitor was added in the concentration range previously used to inhibit CKII activity against natural substrates $(38,54)$. Figure 5 , lanes 1 to 3 , shows that 2,3-diphosphoglycerate strongly inhibits polymerase III transcription of the $\mathrm{RNA}^{\mathrm{Leu}}$ gene in extracts

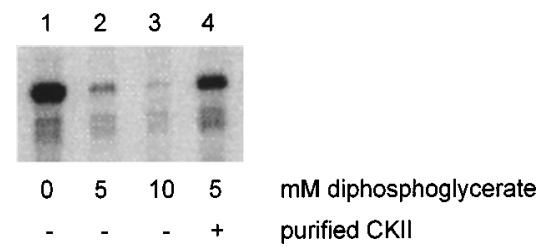

FIG. 5. CKII rescues transcriptional inhibition due to a known CKII inhibitor. Transcription of a tRNA ${ }^{\text {Leu }}$ template in extract from wild-type cells inhibited by the CKII inhibitor 2,3-diphosphoglycerate (lanes 1 to 3 ) and rescued by addition of $100 \mathrm{ng}$ of purified CKII (lane 4) was monitored.

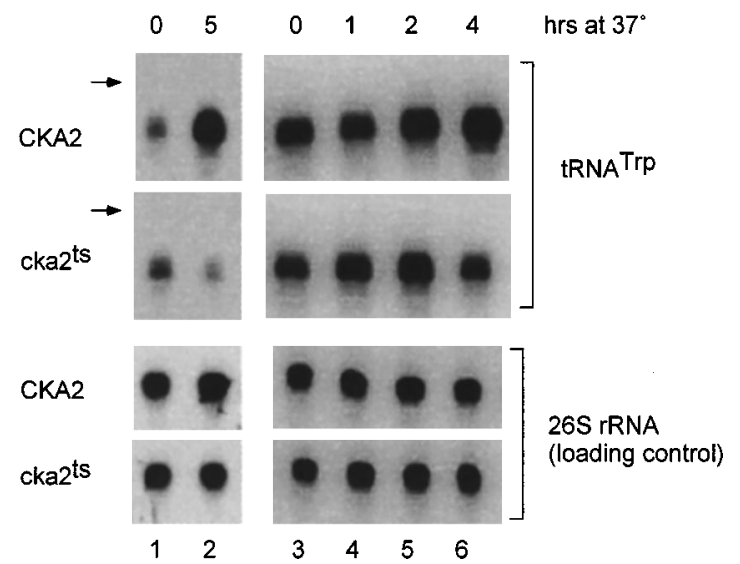

FIG. 6. Transcription by RNA polymerase III in vivo is impaired when CKI is inactivated. In two separate experiments (lanes 1 and 2; lanes 3 to 6), total RNA was isolated from CKA2 and $\mathrm{cka}^{\mathrm{ts}}$ cells cultured for various periods of time at the restrictive temperature $\left(37^{\circ} \mathrm{C}\right)$. Transcription of a tryptophan tRNA gene was monitored by S1 nuclease protection analysis (arrows marks the positions of the full-length probe). Samples were probed for 26S rRNA to check equivalency of loading.

from wild-type (CKA1 CKA2) cells. This result is consistent with a role for CKII in polymerase III transcription. To confirm that this inhibition is due to an effect on CKII, we added purified enzyme to reactions containing the inhibitor. From comparison of lanes 2 and 4 in Fig. 5, it is clear that purified CKII significantly rescues transcription in the presence of the inhibitor. The same result was obtained when the $5 \mathrm{~S}$ rDNA template was used (not shown). These results support the idea that the catalytic activity of CKII is normally required for transcription by RNA polymerase III.

CKII activity is required for polymerase III transcription in vivo. To test whether polymerase III transcription in vivo requires CKII activity, we monitored tRNA synthesis in CKA2 and cka $2^{\text {ts }}$ cells by using an $\mathrm{S} 1$ nuclease protection assay to measure the steady-state level of the intron of tRNA ${ }^{\operatorname{Trp}}$ (12). Since tRNA introns are turned over in the cell with a half-life of less than $3 \mathrm{~min}$ (33), their abundance is an accurate indicator of the level of transcription $(12,21)$. Total RNA was prepared from cells cultured at the permissive or restrictive $\left(37^{\circ} \mathrm{C}\right)$ temperature and hybridized to the tRNA probe and a probe for 26S rRNA (as a loading control). Figure 6 (top panel) shows the pattern of tRNA ${ }^{\mathrm{Trp}}$ transcription in the two strains, before and after the shift to $37^{\circ} \mathrm{C}$. In the first experiment (lanes 1 and 2), cells were cultured at $37^{\circ} \mathrm{C}$ for $5 \mathrm{~h}$. In strain CKA2, the steady-state level of the unprocessed tRNA precursor increases during $5 \mathrm{~h}$ culture at $37^{\circ} \mathrm{C}$. This is expected, since CKA2 cells continue to grow at $37^{\circ} \mathrm{C}$, and is the typical pattern of transcription in wild-type yeast strains grown at $37^{\circ} \mathrm{C}(12)$. Transcription is $\mathrm{cka} 2^{\text {ts }}$ cells, on the other hand, declines slightly by $5 \mathrm{~h}$ of culture at the restrictive temperature. In a separate experiment (lanes 3 to 6), we examined this effect in more detail by taking time points at 1,2 , and $4 \mathrm{~h}$ after the shift to the restrictive temperature. The patterns of tRNA transcription in the strains are similar during the first $2 \mathrm{~h}$ at the restrictive temperature. However, in $\mathrm{cka} 2^{\text {ts }}$ cells, there is a decline in transcription from 2 to $4 \mathrm{~h}$, while transcription increases in CKA2 cells. These results demonstrate that CKII is required for active polymerase III transcription of the tRNA genes in vivo.

Collectively, our results demonstrate that CKII activity in $S$. cerevisiae is required for efficient transcription by RNA polymerase III in vivo and in vitro. 


\section{DISCUSSION}

CKII is required for polymerase III transcription. The central finding of this study is that the enzymatic activity of a ubiquitous eukaryotic protein kinase, CKII, is required for high-level transcription of the 5S and tRNA genes by RNA polymerase III. This requirement for CKII is clear from our in vivo measurements of polymerase III transcription in the cka $2^{\text {ts }}$ mutant: in cka $2^{\text {ts }}$, compared with the wild type, ongoing polymerase III transcription is severely depressed at the restrictive temperature (Fig. 6). This inhibition of polymerase III transcription would at least in part account for the decline of overall RNA synthesis in vivo previously observed when $\mathrm{cka} 2^{\text {ts }}$ cells are shifted to the restrictive temperature (23).

Our in vitro experiments rule out the possibility that the inhibition of polymerase III transcription during culture at the restrictive temperature results indirectly from the failure of other cellular processes that require CKII, for example, processes involved in the synthesis of transcription factors (mRNA transcription, translation). First, we observe the transcription defect in extracts from cka $2^{\text {ts }}$ cells that were not shifted to the restrictive temperature (Fig. 2A) but nonetheless have low CKII activity (Fig. 1B). The low activity of the $c k a 2-8^{t s}$ allele in extracts at the permissive temperature remains unexplained but is not unusual for a $t s$ protein. For example, $t s$ alleles of DNA ligase (30), the TATA-binding protein (49), and DNA topoisomerase II (46) are all known to have low activity in extracts from cells harvested at the permissive temperature. Second, transcription in wild-type extracts is sensitive to an inhibitor of CKII, and the effect of this inhibitor on transcription is relieved by added CKII (Fig. 5). These results argue for a direct involvement of CKII in polymerase III transcription.

The CKII add-back experiment in Fig. 4 provides the strongest support for the conclusion that the transcription defect in $\mathrm{cka} 2^{\text {ts }}$ extracts directly results from the lack of CKII activity. However, while we reproducibly obtain a dose-dependent rescue of polymerase III transcription, the rescue is relatively inefficient. This is revealed if one compares the amount of endogenous CKII activity in CKA2 extracts with the amount of CKII activity that stimulates transcription in cka $2^{\text {ts }}$ extracts. The endogenous CKII in CKA2 on average incorporated 6,410 $\mathrm{cpm} / 30 \mu \mathrm{g}$ of extract. Since CKII does not stimulate transcription in wild-type extracts, at this level CKII is saturating for polymerase III transcription (not shown). On the basis of the plot in Fig. 4A, the wild-type level of bulk CKII activity and therefore maximal transcription should be obtained by adding $33 \mathrm{ng}$ of CKII to $30 \mu \mathrm{g}$ of $\mathrm{cka} 2^{\text {ts }}$ extract. Stimulation of transcription, however, is observed well beyond this amount of CKII (Fig. 4B; compare lanes 2 and 4 and lanes 7 and 10). We do not know why the rescue is inefficient, but several possibilities come to mind. Perhaps CKII cannot easily associate with its relevant target in a whole cell extract, or, more interestingly, perhaps the stationary-phase CKII that we used is modified in a way that is not optimal for interaction with its target in growing cells. These possibilities are open to experimental investigation.

Possible mechanisms of regulation of polymerase III transcription by CKII. CKII-depleted extracts produce transcripts that start and stop at the correct sites, suggesting that neither start site selection nor recognition of the terminator requires CKII. Short transcripts do not accumulate in CKII-depleted extract, and so there is no abnormal pausing during chain elongation. CKII then is most likely required for a step in the assembly of transcription factor-DNA complexes and/or transcription initiation. What is the CKII-responsive target involved in the step that is sensitive to CKII? There are two possibilities: first, that the target is a component of the basal transcription machinery; and second, that it is an accessory activity involved in transcription.

RNA polymerase III, TFIIIB, TFIIIC, and TFIIIA are required for basal polymerase III transcription. Among these components, the polymerase, TFIIIB, and TFIIIC are possible targets; TFIIIA cannot be a target since CKII is required for transcription of the tRNA genes but TFIIIA is not used at tRNA promoters $(7,18,31)$. RNA polymerase III, TFIIIB, and TFIIIC in $S$. cerevisiae all contain subunits that are phosphoproteins in vivo. Specifically, the $23-$ and $19-\mathrm{kDa}$ subunits of the polymerase (3), the TATA-binding protein subunit of TFIIIB (19), and the 138-, 131-, and 95-kDa subunits of TFIIIC (11) are phosphoproteins. The phosphorylated subunits also include the CKII consensus site, Ser(Thr)-X-Xacidic (polymerase III [14, 61]; TATA-binding protein [16, 22]; 138-, 131-, and 95-kDa subunits of TFIIIC [35, 37, 52]).

The possible targets classified as accessory activities include inhibitors that might be regulated (inactivated) by CKII. Polymerase III transcription is inhibited by the formation of nucleosomes over promoter DNA (60), by the protein Dr1, which interferes with TFIIIB function $(28,58)$, and by a putative repressor that is regulated by protein phosphatase $2 \mathrm{~A}(52)$. We have tested if CKII is required for nucleosome assembly in the extracts used for our transcription experiments, since under defined conditions, the extracts also support chromatin assembly (48). We observe the same level of assembly in CKA2 and cka $2^{\text {ts }}$ extracts, suggesting that the role of CKII in polymerase III transcription does not involve an effect on nucleosome assembly. Further biochemical studies are in progress to identify the target involved in polymerase III transcription that is responsive to CKII.

Diverse functions of CKII in the regulation of nuclear transcription. In our experiments comparing CKA2 and cka2ts extracts, we were unable to detect an effect of CKII depletion on basal transcription by either RNA polymerase I or RNA polymerase II. We are therefore reassured that the inhibition of polymerase III transcription in $\mathrm{cka} 2^{\text {ts }}$ extract is not simply the result of a general inhibition of RNA synthesis in vitro. If CKII is involved in polymerase II transcription in $S$. cerevisiae, then its function most likely is restricted to the regulation of transactivators as in higher eukaryotes (reviewed in references 29, 36, and 39). Our failure to detect an effect of CKII on polymerase I initiation suggests that the stimulation of polymerase I transcription by CKII observed in nuclei isolated from mammalian cells (2) may have been due to an effect on elongation, as previously noted (see Discussion in reference 6). Therefore, although CKII is implicated as a positive-acting factor in the regulation of transcription by all three nuclear RNA polymerases, the mechanism of its function is distinctly different from one class of gene to the next.

Protein kinases and the regulation of polymerase III transcription. Previous studies have clearly demonstrated an important role for protein kinases in the regulation of polymerase III transcription, both in repression and in induction. Mitotic repression of polymerase III transcription in metazoan cells is mediated by $\mathrm{p} 34^{c d c 2}$ and another, unidentified protein kinase $(20,57)$, and the induction of polymerase III transcription in virally infected mammalian cells involves phosphorylation of TFIIIC by an unidentified kinase $(27,59)$. The increased polymerase III transcription that results when Drosophila cells are stimulated with phorbol ester presumably involves activation of protein kinase C (17). Our discovery adds an oncogenic protein kinase, CKII, to the kinases known to be directly or indirectly involved in the regulation of transcription by RNA polymerase III. Collectively, these results suggest that polymerase 
III transcription in eukaryotes is controlled by multiple protein kinases. These protein kinases may act as part of a regulatory network to determine the output of polymerase III gene products.

What might the physiological role of CKII be in the context of this regulatory network? CKII appears to be important for both cell cycle and growth control in eukaryotic cells (reviewed in references 36 and 39). Its further role in polymerase III transcription may provide a pathway for the coordination of polymerase III transcription with cell cycle events and/or growth state. CKII is required for cell cycle progression at multiple points in interphase $(23,43)$. Since transcription is elevated in interphase $(20,24,57)$, the positive role of CKII in both progression through interphase and polymerase III transcription might provide a mechanism for maintaining high transcription during interphase. Polymerase III transcription is strictly regulated according to growth rate in mammalian (53) and yeast (19) cells. In some mammalian cell types, the level of CKII activity is transiently elevated in response to growth stimulation (9), which results in high transcription, and may be repressed in stationary phase, when transcription is repressed (2). CKII may therefore be important for coordinating polymerase III transcription with overall growth rate. These functions of CKII would help to ensure that the supply of the tRNAs and 5S rRNA is appropriate for the physiological status of the cell.

\section{ACKNOWLEDGMENTS}

We are grateful to David Hanna, Ashok Bidwai, and Claiborne Glover (University of Georgia) for the generous gifts of strains YDH 6 and YDH 8 and for purified CKII and to Claiborne Glover for communication of results prior to publication. We also thank members of the Schultz laboratory for fruitful discussions and Claiborne Glover, Charlotte Spencer, Jim Stone, and Grant McFadden for comments on the manuscript.

This work was supported by an establishment grant from the Alberta Heritage Foundation for Medical Research, pilot funding from the Cancer Research Society, and an operating grant from the National Cancer Institute of Canada with funds from the Canadian Cancer Society. M.C.S. is a Scholar of the Medical Research Council of Canada.

\section{REFERENCES}

1. Baker, R. E., and B. D. Hall. 1984. Structural features of yeast tRNA genes which affect transcription factor binding. EMBO J. 3:2793-2800.

2. Belenguer, P., V. Baldin, C. Mathieu, H. Prats, M. Bensaid, G. Bouche, and F. Amalric. 1989. Protein kinase NII and the regulation of rDNA transcription in mammalian cells. Nucleic Acids Res. 17:6625-6636.

3. Bell, G. I., P. Valenzuela, and W. J. Rutter. 1977. Phosphorylation of yeast DNA-dependent RNA polymerases in vivo and in vitro. Isolation of enzymes and identification of phosphorylated subunits. J. Biol. Chem. 252:3082-3091.

4. Bidwai, A. P., D. E. Hanna, and C. V. C. Glover. 1992. Purification and characterization of casein kinase II (CKII) from $\Delta c k a 1 \Delta c k a 2$ Saccharomyces cerevisiae rescued by Drosophila CKII subunits. The free catalytic subunit of casein kinase II is not toxic in vivo. J. Biol. Chem. 267:18790-18796.

5. Bidwai, A. P., J. C. Reed, and C. V. C. Glover. 1994. Casein kinase II of Saccharomyces cerevisiae contains two distinct regulatory subunits, $\beta$ and $\beta^{\prime}$. Arch. Biochem. Biophys. 309:348-355.

6. Caizergues-Ferrer, M., P. Belenguer, B. Lapeyre, F. Amalric, M. O. Wallace, and M. O. J. Olson. 1987. Phosphorylation of nucleolin by a nucleolar type NII protein kinase. Biochemistry 26:7876-7883.

7. Camier, S., A.-M. Dechampesme, and A. Sentenac. 1995. The only essential function of TFIIIA in yeast is the transcription of 5S rRNA genes. Proc. Natl. Acad. Sci. 92:9338-9342.

8. Cardenas, M. E., Q. Dang, C. V. C. Glover, and S. E. Gasser. 1992. Casein kinase II phosphorylates the eukaryote-specific C-terminal domain of topoisomerase II in vivo. EMBO J. 11:1785-1796.

9. Carroll, D., and D. R. Marshak. 1989. Serum-stimulated cell growth causes oscillations in casein kinase II activity. J. Biol. Chem. 264:7345-7348.

10. Chen-Wu, J. L.-P., R. Padmanabha, and C. V. C. Glover. 1988. Isolation, sequencing, and disruption of the $C K A 1$ gene encoding the alpha subunit of yeast casein kinase II. Mol. Cell. Biol. 8:4981-4990.
11. Conesa, C., R. N. Swanson, P. Schultz, P. Oudet, and A. Sentenac. 1993. On the subunit composition, stoichiometry, and phosphorylation of the yeast transcription factor TFIIIC/ $\tau^{*}$. J. Biol. Chem. 268:18047-18052

12. Cormack, B. P., and K. Struhl. 1992. The TATA-binding protein is required for transcription by all three nuclear RNA polymerases in yeast cells. Cell 69:685-696.

13. Cross, F. R., and A. H. Tinkelenberg. 1989. A potential positive feedback loop controlling $C L N 1$ and $C L N 2$ gene expression at the start of the yeast cell cycle. Cell 65:875-883.

14. Dequard-Chablat, M., M. Riva, C. Carles, and A. Sentenac. 1991. RPC19, the gene for a subunit common to yeast RNA polymerases A (I) and C (III). J. Biol. Chem. 266:15300-15307.

15. Dunstan, H. M., L. S. Young, and K. U. Sprague. 1994. tRNA $\mathrm{IIAU}_{\mathrm{Ile}}$ (TFIIIR) plays an indirect role in silkworm class III transcription in vitro and inhibits low-frequency DNA cleavage. Mol. Cell. Biol. 14:3596-3603.

16. Eisenmann, D. M., C. Dollard, and F. Winston. 1989. SPT15, the gene encoding the yeast TATA binding factor TFIID, is required for normal transcription initiation in vivo. Cell 58:1183-1191.

17. Garber, M. E., A. Vilalta, and D. L. Johnson. 1994. Induction of Drosophila RNA polymerase III gene expression by the phorbol ester $12-O$-tetradecanoylphorbol-13-acetate (TPA) is mediated by transcription factor IIIB. Mol. Cell. Biol. 14:339-347.

18. Geiduschek, E. P., and G. A. Kassavetis, 1992. RNA polymerase III transcription complexes, p. 247-280. In S. L. McKnight and K. Yamamoto (ed.), Transcriptional regulation. Cold Spring Harbor Laboratory Press, Cold Spring Harbor, N.Y.

19. Ghavidel, A., and M. C. Schultz. Unpublished data.

20. Gottesfeld, J. M., V. J. Wolf, T. Dang, D. J. Forbes, and P. Hartl. 1994 Mitotic repression of RNA polymerase III transcription in vitro mediated by phosphorylation of a TFIIIB component. Science 263:81-84.

21. Guzder, S. N., H. Qiu, C. H. Sommers, P. Sung, L. Prakash, and S. Prakash. 1994. DNA repair gene $R A D 3$ of $S$. cerevisiae is essential for transcription by RNA polymerase II. Nature (London) 367:91-94.

22. Hahn, S., S. Buratowski, P. A. Sharp, and L. Guarente. 1989. Isolation of the gene encoding the yeast TATA binding protein TFIID: a gene identical to the SPT15 suppressor of Ty element insertions. Cell 58:1173-1181.

23. Hanna, D. E., A. Rethinaswamy, and C. V. C. Glover. 1995. Casein kinase II is required for cell cycle progression during G1 and G2/M in Saccharomyces cerevisiae. J. Biol. Chem. 270:25904-25914.

24. Hartl, P., J. Gottesfeld, and D. J. Forbes. 1993. Mitotic repression of transcription in vitro. J. Cell Biol. 120:613-624.

25. Hassouna, N., B. Michot, and J.-P. Bachellerie. 1984. The complete nucleotide sequence of mouse $28 \mathrm{~S}$ rRNA gene. Implications for the process of size increase of the large subunit rRNA in higher eukaryotes. Nucleic Acids Res. 12:3563-3583.

26. Hathaway, G. M., T. H. Lubben, and J. A. Traugh. 1980. Inhibition of casein kinase II by heparin. J. Biol. Chem. 255:8038-8041.

27. Hoeffler, W. K., R. Kovelman, and R. G. Roeder. 1988. Activation of transcription factor IIIC by the adenovirus E1A protein. Cell 53:907-920.

28. Inostroza, J. A., F. H. Mermelstein, I. Ha, W. S. Lane, and D. Reinberg. 1992. Dr1, a TATA-binding protein-associated phosphoprotein and inhibitor of class II gene transcription. Cell 70:477-489.

29. Issinger, O.-G. 1993. Casein kinases: pleiotropic mediators of cellular regulation. Pharmacol. Ther. 59:1-30.

30. Johnston, L. H., and K. A. Nasmyth. 1978. Saccharomyces cerevisiae cell cycle mutant $c d c 9$ is defective in DNA ligase. Nature (London) 274:891-893.

31. Kassavetis, G. A., B. R. Braun, L. H. Nguyen, and E. P. Geiduschek. 1990. S cerevisiae TFIIIB is the transcription initiation factor proper of RNA polymerase III, while TFIIIA and TFIIIC are assembly factors. Cell 60:235-245.

32. Klekamp, M. S., and P. A. Weil. 1982. Specific transcription of homologous class III genes in yeast-soluble cell-free extracts. J. Biol. Chem. 257:84328441.

33. Knapp, G., J. S. Beckmann, P. F. Johnson, S. A. Fuhrman, and J. Abelson. 1978. Transcription and processing of intervening sequences in yeast tRNA genes. Cell 14:221-236.

34. Kuenzel, E. A., and E. G. Krebs. 1985. A synthetic peptide substrate specific for casein kinase II. Proc. Natl. Acad. Sci. USA 82:737-741.

35. Lefebvre, O., C. Carles, C. Conesa, R. N. Swanson, F. Bouet, M. Riva, and A. Sentenac. 1992. TFC3: gene encoding the B-block binding subunit of the yeast transcription factor IIIC. Proc. Natl. Acad. Sci. USA 89:10512-10516.

36. Litchfield, D. W., and B. Lüscher. 1993. Casein kinase II in signal transduction and cell cycle regulation. Mol. Cell. Biochem. 127/128:187-199.

37. Marck, C., O. Lefebvre, C. Carles, M. Riva, N. Chaussivert, A. Ruet, and A. Sentenac. 1993 The TFIIIB-assembling subunit of yeast transcription factor TFIIIC has both tetratricopeptide repeats and basic helix-loop-helix motifs. Proc. Natl. Acad. Sci. USA 90:4027-4031.

38. Mayrand, S. H., P. Dwen, and T. Pederson. 1993. Serine/threonine phosphorylation regulates binding of $\mathrm{C}$ hnRNP proteins to pre-mRNA. Proc. Natl. Acad. Sci. USA 90:7764-7768.

39. ole-MoiYoi, O. K. 1995. Casein kinase II in theileriosis. Science 267:834-836.

40. ole-MoiYoi, O. K., W. C. Brown, K. P. Iams, A. Nayar, T. Tsukamoto, and M. D. Macklin. 1993. Evidence for the induction of casein kinase II in bovine 
lymphocytes transformed by the intracellular protozoan parasite Theileria parva. EMBO J. 12:1621-1631.

41. Padmanabha, R., J. L.-P. Chen-Wu, D. E. Hanna, and C. V. C. Glover. 1990 Isolation, sequencing, and disruption of the yeast $C K A 2$ gene: casein kinase II is essential for viability in Saccharomyces cerevisiae. Mol. Cell. Biol. 10: 4089-4099.

42. Padmanabha, R., and C. V. C. Glover. 1987. Casein kinase II of yeast contains two distinct $\alpha$ polypeptides and an unusually large $\beta$ subunit. J. Biol. Chem. 262:1829-1835.

43. Pepperkok, R., P. Lorenz, W. Ansorge, and W. Pyerin. 1994. Casein kinase II is required for transition of $G_{0} / G_{1}$, early $G_{1}$, and $G_{1} / S$ phases of the cell cycle. J. Biol. Chem. 269:6986-6991.

44. Pepperkok, R., P. Lorenz, R. Jakobi, W. Ansorge, and W. Pyerin. 1991. Cell growth stimulation by EGF: inhibition through antisense-oligodeoxynucleotides demonstrates important role of casein kinase II. Exp. Cell Res. 197: 245-253.

45. Pinna, L. A. 1990. Casein kinase 2: an "eminence grise" in cellular regulation? Biochim. Biophys. Acta 1054:267-284.

46. Schultz, M. C., S. J. Brill, Q. Ju, R. Sternglanz, and R. H. Reeder. 1992. Topoisomerases and yeast rRNA transcription: negative supercoiling stimulates initiation and topoisomerase activity is required for elongation. Genes Dev. 6:1332-1341.

47. Schultz, M. C., S. Y. Choe, and R. H. Reeder. 1991. Specific initiation by RNA polymerase I in a whole-cell extract from yeast. Proc. Natl. Acad. Sci. USA 88:1004-1008.

48. Schultz, M. C., D. H. Hockman, T. A. A. Harkness, W. I. Garinther, and B. A. Altheim. Mechanism of replication-independent chromatin assembly in yeast. Submitted for publication.

49. Schultz, M. C., R. H. Reeder, and S. Hahn. 1992. Variants of the TATAbinding protein can distinguish subsets of RNA polymerase I, II and III promoters. Cell 69:697-702.

50. Seldin, D. C., and P. Leder. 1995. Casein kinase II $\alpha$ transgene-induced murine lymphoma: relation to theileriosis in cattle. Science 267:894-897.

51. Sikorski, R. S., and P. Heiter. 1989. A system of shuttle vectors and yeast host strains designed for efficient manipulation of DNA in S. cerevisiae. Genetics 122:19-27.

52. Swanson, R. N., C. Conesa, O. Lefebvre, C. Carles, A. Ruet, E. Quemeneur, J. Gagnon, and A. Sentenac. 1991. Isolation of TFC1, a gene encoding one of two DNA-binding subunits of yeast transcription factor $\tau$ (TFIIIC). Proc. Natl. Acad. Sci. USA 88:4887-4891.

53. Tower, J., and B. Sollner-Webb. 1988. Polymerase III transcription factor B activity is reduced in extracts of growth-restricted cells. Mol. Cell. Biol. 8:1001-1005.

54. Tuazon, P. T., and J. A. Traugh. 1991. Casein kinase I and II-multipotential serine protein kinases: structure, function, and regulation. Adv. Second Messenger Phosphoprotein Res. 23:123-164.

55. van Zyl, W., W. Huang, A. A. Sneddon, M. Stark, S. Camier, M. Werner, C Marck, A. Sentenac, and J. R. Broach. 1992. Inactivation of the protein phosphatase $2 \mathrm{~A}$ regulatory subunit results in morphological and transcriptional defects in Saccharomyces cerevisiae. Mol. Cell. Biol. 12:4946-4959.

56. Voit, R., A. Schnapp, A. Kuhn, H. Rosenbauer, P. Hirschmann, H. G. Stunnenberg, and I. Grummt. 1992. The nucleolar transcription factor mUBF is phosphorylated by casein kinase II in the C-terminal hyperacidic tail which is essential for transactivation. EMBO J. 6:2211-2218.

57. White, R. J., T. M. Gottlieb, C. S. Downes, and S. P. Jackson. 1995. Mitotic regulation of a TATA-binding-protein-containing complex. Mol. Cell. Biol. 15:1983-1992.

58. White, R. J., B. C.-E. Khoo, J. A. Inostroza, D. Reinberg, and S. P. Jackson. 1994. Differential regulation of RNA polymerases I, II and III by the TBPbinding repressor Dr1. Science 266:448-490.

59. White, R. J., D. Stott, and P. W. J. Rigby. 1990. Regulation of RNA polymerase III transcription in response to Simian virus 40 transformation. EMBO J. 9:3713-3721.

60. Wolffe, A. P. 1992. Chromatin. Structure and function. Academic Press, London.

61. Woychik, N. A., S.-M. Liao, P. A. Kolodziej, and R. A. Young. 1990. Subunits shared by eukaryotic nuclear RNA polymerases. Genes Dev. 4:313-323. 